\title{
O Significado da Morte para Crianças, Adolescentes, Adultos e Idosos
}

\section{The Meaning of Death for Children, Adolescents, Adults and the Elderly}

Olavo Franco Ferreira Filho

O medo da morte continua presente mundialmente. O que mudou? A forma de lidar com ela e com os doentes prestes a enfrentá-la. As inovações tecnológicas e farmacêuticas propiciam ao profissional de saúde tratar e restaurar a vida, mas restringem a autonomia dos pacientes. A maneira de conviver com pacientes graves e/ou terminais e de comunicar notícias difíceis a pacientes e familiares passou a ser impessoal e solitária, pois parece não haver um consenso nos ensinamentos que os profissionais adquirem sobre o assunto durante a sua formação acadêmica ${ }^{1}$.

O conceito de morte envolve três dimensões: irreversibilidade, não funcionalidade e universalidade. A criança não compreende estas dimensões e sofre quando não há suporte para o enfrentamento de situações de perda. Não ter com quem conversar e obter esclarecimentos a respeito pode deixá-la confusa e desamparada diante de sua dor $^{2,3}$. $\mathrm{O}$ adolescente compreende de modo semelhante ao adulto, entende o conceito de morte tornando-a um evento mais real. Porém, nesta faixa etária, o ser humano apresenta as suas melhores condições físicas e cognitivas, o que o leva a ter uma sensação de liberdade e onipotência, tornando-o de alto risco para a ocorrência de acidentes e mortes precoces ${ }^{4}$. Assim, também falta ao adolescente alguém com quem conversar, alertando-o sobre como o seu comportamento pode prejudicar a sua saúde.

$\mathrm{O}$ medo da morte parece atingir seu auge na vida adulta de meia-idade, após o que diminui sensivelmente. Adultos mais velhos falam mais sobre a morte e a temem menos. Religiosos costumam temer menos a morte. Por outro lado, os que apresentam altos níveis de ansiedade e estresse sentem mais medo dela. Muitos adultos preparam-se para a morte de forma prática, fazendo seguros de vida ou escrevendo seu testamento. Ocorrem sinais de mudanças profundas na personalidade imediatamente antes da morte, o que inclui maior dependência e docilidade, menos emoções e desejo de afirmação ${ }^{5}$.

Algumas questões geram controvérsias em relação à morte, como o suicídio assistido e a eutanásia. Atualmente, ocorre maior interesse na compreensão e enfrentamento da morte de maneira realista e compassiva.

Kübler-Ross, em seu livro A Morte e o Morrer, escrito em 1985, que já está na nona edição, por meio de entrevistas com pacientes gravemente doentes e desenganados de um hospital de Chicago, chegou aos cinco estágios emocionais pelos quais eles passam durante o processo de morrer: negação, raiva, barganha, depressão e aceitação. As pesquisas não conseguem apoiar a afirmação de que todos os adultos mostram todos os cinco ou que os estágios, necessariamente, ocorrem nessa ordem. O ingrediente mais comum é a depressão. Além disso, o livro descreve as dificuldades encontradas pela equipe multiprofissional ao lidar com o paciente, as notícias difíceis e os familiares. Especialmente os médicos têm grande dificuldade de falar a verdade ao paciente e familiares. Porém, a autora do livro afirma que o maior 
problema não é o que falar, mas como fazê-lo. A reação dos pacientes não depende do conteúdo da notícia difícil. É muito mais importante a maneira como ela é informada ${ }^{1}$.

As escolas médicas, de modo geral, preocupam-se com este assunto, introduzindo ou reforçando em seus currículos a comunicação com paciente e familiares. Mas ainda existem escolas que ignoram o assunto, e o estudante de Medicina, apesar de ter fácil acesso a um abundante material científico, não recebe qualquer treinamento a respeito. Nesta edição de nossa revista encontraremos alguns trabalhos que darão suporte a este tema.

Assim, como sugerido há 30 anos por Kubler-Ross, os profissionais deveriam refletir sobre sua própria morte como aspecto componente e central da vida, auxiliando a transmissão de valores humanos aos alunos e facilitando a lida com os pacientes e seus familiares.

\section{REFERÊNCIAS}

1. Afonso, SBC. Resenha do livro "Sobre a Morte e o Morrer". Ciênc. saúde coletiva, 18(9), Rio de Janeiro, 2013.

2. Nunes, DC, Carraro, L, Jou, GI, Sperb, TM. As crianças e o conceito de morte. Psicologia: Reflexão e Crítica, 11(3), 579590, 1998.

3. Vendruscolo, J. Visão da criança sobre a morte. Medicina (Ribeirão Preto), 38(1), 26-33, 2005.

4. Kovács, MJ. Morte e desenvolvimento humano (4a ed.). São Paulo: Casa do Psicólogo, 2002.

5. Papalia, DE; Olds, SW; Feldman, RD. Desenvolvimento humano. Porto Alegre: Artmed, 2006.

\section{ENDEREÇO PARA CORRESPONDÊNCIA}

Associação Brasileira de Educação Médica - ABEM

SCN Quadra 2, Bloco D, Sala 1021, Asa Norte - Brasília

CEP 70712-903 - DF

\section{COLABORAÇÃO DOS AUTORES}

Autor único.

\section{CONFLITO DE INTERESSES}

Autor declara não haver. 